Discussion Paper No. 12-022

Backwards Integration and Strategic Delegation

Matthias Hunold, Lars-Hendrik Röller, and Konrad Stahl

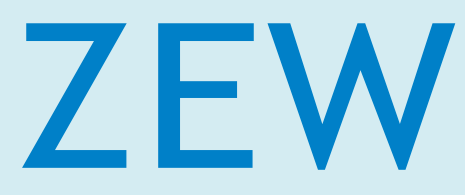

Zentrum für Europäische Wirtschaftsforschung $\mathrm{GmbH}$ Centre for European Economic Research 
Discussion Paper No. 12-022

\title{
Backwards Integration and Strategic Delegation
}

\author{
Matthias Hunold, Lars-Hendrik Röller, \\ and Konrad Stahl
}

Download this ZEW Discussion Paper from our ftp server:

http://ftp.zew.de/pub/zew-docs/dp/dp12022.pdf

Die Discussion Papers dienen einer möglichst schnellen Verbreitung von neueren Forschungsarbeiten des ZEW. Die Beiträge liegen in alleiniger Verantwortung der Autoren und stellen nicht notwendigerweise die Meinung des ZEW dar.

Discussion Papers are intended to make results of ZEW research promptly available to other economists in order to encourage discussion and suggestions for revisions. The authors are solely responsible for the contents which do not necessarily represent the opinion of the ZEW. 


\section{Non-technical summary}

The acquisition of ownership rights by a firm in its suppliers is a common feature in various industries. Often, these acquisitions are reduced to a participation in the target's cash flow, and not associated with any control. This form of backwards integration has heretofore not been of great concern to the researchers and practitioners of competition policy. The consensus was that competition would not be harmed by such "silent" acquisitions.

Against this backdrop, we analyze how a non-controlling partial backwards acquisition in the efficient supplier affects up- and downstream prices. When the efficient supplier also sells to downstream rivals, the acquiring downstream firm internalizes that an increase in the rivals' sales increases upstream profits. Hence the acquiring downstream firm has an incentive to increase its sales price as this increases rivals' sales. Its rivals react by also increasing theirs - and this the more, the more competitive the downstream industry is.

Full vertical integration, associated with controlling the target's decisions, instead, leads to decreasing downstream prices as double marginalization is avoided. It is shown to be less profitable than passive backwards integration, as long as competition is sufficiently intense in both, downstream and upstream markets. This has an important implication: When acquiring shares in the upstream firm, downstream firms strategically abstain from vertical control, and with this allow the efficient upstream firm to stick to a high transfer price. This is a very peculiar form of the so-called strategic delegation of decisions.

With this paper, we show that passive partial backwards integration should indeed be of concern to competition authorities. 


\section{Das Wichtigste in Kürze}

Der Erwerb von Eigentumsrechten eines Unternehmens an seinen Zulieferern ist ein häufig beobachtetes Phänomen. Er erfolgt oft, ohne dass damit eine Kontrolle der Entscheidungen des Zulieferers einhergeht. Interessanterweise wurde bisher der Erwerb solcher nichtkontrollierender Anteile weder durch die Forschung noch durch die Wettbewerbsbehörden einer näheren Betrachtung unterzogen. Man hat ihm keine wettbewerbsverzerrenden Konsequenzen beigemessen.

In der vorliegenden Arbeit untersuchen wir daher die Wirkungen eines nicht kontrollierenden Erwerbs von Anteilen am effizienten - und damit auch die Wettbewerber beliefernden - Zulieferer auf die Preisbildung im Zuliefer- wie auch im Absatzmarkt. Durch die Anteile am Zulieferer berücksichtigt das nachgelagerte Unternehmen die Wirkung seiner Preissetzung auf die Absatzmengen seiner Wettbewerber, da deren Mehrabsätze den Zulieferergewinn steigern. Folglich kann das beteiligte Unternehmen seinen Absatzpreis profitabel erhöhen, woraufhin die Wettbewerber nachziehen. Alle Preise steigen, und zwar umso mehr, je intensiver der Wettbewerb im Absatzmarkt ist.

Kontrastierend dazu betrachten wir den Fall, in dem das nachgelagerte Unternehmen seinen Zulieferer gänzlich erwirbt, also auch seine Preisbildung kontrolliert. In diesem Fall verschwindet die in vertikal verflochtenen Unternehmen zu beobachtende doppelte Marginalisierung und die Absatzpreise fallen. Trotz der damit verbundenen Effizienzsteigerung ist diese gänzliche vertikale Integration für beide, das erwerbende wie auch das erworbene Unternehmen, weniger profitabel als der Erwerb nicht-kontrollierender Anteile, sofern der Wettbewerbsdruck auf beiden Marktstufen einigermaßen hoch ist.

Folglich wird das erwerbende Unternehmen die Anteile an seinem Lieferanten nur bis zu dem Punkt erhöhen, oberhalb dessen es den Lieferanten kontrollieren würde. Dadurch, dass der Erwerber auf Kontrolle verzichtet, erlaubt er dem Lieferanten sich auf hohe Zulieferpreise festzulegen. Somit steigen bei einer nicht-kontrollierenden Rückwärtsbeteiligung die Absatzpreise im Vergleich zu vollständiger Integration und Separation. Dies ist ein besonders interessantes Beispiel für die strategische Delegation von Entscheidungen.

Insgesamt zeigen wir damit, dass die Akquisition von passiven Eigentumsrechten den Wettbewerbsbehörden durchaus eine nähere Beobachtung wert sein sollte. 


\title{
Backwards Integration and Strategic Delegation
}

\author{
Matthias Hunold* \\ Lars-Hendrik Röller ${ }^{\dagger}$ \\ Konrad Stahl ${ }^{\ddagger}$
}

March 19, 2012

\begin{abstract}
We analyze the effects of downstream firms' acquisition of pure cash flow rights in an efficient upstream supplier when all firms compete in prices. With an acquisition, downstream firms internalize the effects of their actions on their rivals' sales. Double marginalization is enhanced. Whereas full vertical integration would lead to decreasing, passive backwards ownership leads to increasing downstream prices and is more profitable, as long as competition is sufficiently intensive. Downstream acquirers strategically abstain from vertical control, inducing the efficient supplier to commit to high prices. All results are sustained when upstream suppliers are allowed to charge two part tariffs.
\end{abstract}

JEL classification: L22, L40

Keywords: double marginalization, strategic delegation, vertical integration, partial ownership, common agency

*ZEW Centre for European Economic Research, Mannheim and MaCCi, hunold@zew.de ${ }^{\dagger}$ German Federal Chancellery, Berlin and CEPR

${ }^{\ddagger}$ Department of Economics, University of Mannheim, CEPR, CESifo and ZEW, kos@econ.unimannheim.de

We are grateful to the Deutsche Forschungsgemeinschaft (SFB TR-15) for supporting this research; to Johannes Muthers, Volker Nocke, Fausto Pannunzi, Marco Ottaviani, David Sauer, Nicolas Schutz and Yossi Spiegel for constructive comments; and to Christoph Wolf for competent research assistance. 


\section{Introduction}

Passive ownership rights across firms, horizontal and even more so vertical ones, are very common, but have traditionally not been of welfare concern, and thus of competition policy. ${ }^{1}$ While horizontal cross-shareholdings are a well-known strategy to anti-competitively relax competition, ${ }^{2}$ the competitive effects of vertical ownership arrangements are more controversial. Of prominent concern is foreclosure that restricts non-integrated firms' supply, or their access to customers. While the classic Chicago challenge is that vertical mergers are competitively neutral at worst (Bork, 1978; Posner, 1976), several arguments are around of how vertical mergers can yield higher consumer prices, or even foreclosure. The arguments rely on particular assumptions, such as additional commitment power of the integrated firm (Ordover et al., 1990), secret contract offers (Hart and Tirole, 1990), or costs of switching suppliers (Chen, 2001). ${ }^{3}$

In all these models, the authors compare allocations involving completely non-integrated with those involving fully integrated firms, where integration involves a move from no control of the target firm's instruments nor participation in its returns, to full control over the instruments employed by the target firm and full ownership of its returns. Partial ownership, either non-controlling or controlling, is not considered. Yet even hindsight suggests that empirically, partial vertical ownership is the rule rather than the exception (see e.g. Allen and Phillips, 2000; Fee et al., 2006). However, there is very little formal analysis on its competitive effects, and with it of the central question: Is passive partial backwards integration really as innocent as believed heretofore, with respect to anti-competitive effects such as increasing prices or foreclosure?

This is the question we address in the present paper. Our focus is on passive ownership interests that price setting downstream firms may hold in their suppliers, where passive ownership involves pure cash flow rights, i.e. claims on the target's profits, without controlling its decisions. We consider a downstream market involving firms offering horizontally differentiated products, and an upstream homogeneous product market with firms producing at different levels of marginal costs. Under effective upstream competition, where the cost differences between the efficient and the other suppliers are not very large, that supplier serves all downstream firms, but is restricted in its price setting by the second efficient supplier.

While increasing passive downwards ownership of an upstream supplier in downstream firms tends to reduce double marginalization and thus downstream prices, passive backwards ownership of downstream in upstream firms does not reduce, but exacerbate double marginalization. The reasons are as follows: an increasing participation in the profits of its upstream supplier leads the downstream firm to soften its reaction to an upstream price increase. The upstream supplier incorporates this, and thus increases the upstream price.

\footnotetext{
${ }^{1}$ The topic has recently received more attention. In 2011, Joaquín Almunia, the EU commissioner for competition policy, voiced that there is potentially an enforcement gap as the EU Merger Regulation does not apply to minority shareholdings. See "Merger Regulation in the EU after 20 years", co-presented by the IBA Antitrust Committee and the European Commission, March 10, 2011.

${ }^{2}$ See Flath (1991) for an early analysis of the profitability of horizontal partial ownership, and more recently Brito et al. (2010) or Karle et al. (2011).

${ }^{3}$ Other explanations include input choice specifications (Choi and Yi, 2000), two-part tariffs (Sandonis and Fauli-Oller, 2006), exclusive dealing contracts (Chen and Riordan, 2007), only integrated upstream firms (Bourreau et al., 2011) and information leakages (Allain et al., 2010).
} 
Whereas the two effects compensate each other, the acquiring firm, via its participation in the efficient supplier's profits, incorporates indirectly the effect of its own actions on the downstream competitors' sales quantities, as long as the downstream competitors are served by the same efficient upstream firm. That downstream firm now has an incentive to raise its price. In turn, strategic complementarity induces all downstream competitors to increase theirs. ${ }^{4}$

We also show that the possibility to raise downstream prices incentivizes downstream firms to acquire passive interests in the efficient upstream supplier. Thus, in equilibrium, there will be backwards acquisition, as long as competition is sufficiently intense in both markets. Also, in contrast to what one might expect, partial backwards acquisition by one active firm does not invite the foreclosure of downstream competitors. Indeed, the competitors benefit, via increasing equilibrium prices, from the acquiring firm's decision.

This acquisition, however, takes place short of a level at which the downstream firm takes control over the upstream target's pricing decisions. If it did, the upstream firm would lose its power to commit to high prices, and thus all downstream prices would decrease. Hence in the world analyzed here, backwards acquisitions have an anti-competitive effect only if they are passive. In the extension section, we show that backwards acquisition is more profitable for the participating firms than full merger, and that all the effects hold even when the upstream suppliers are allowed to charge two-part tariffs, that typically remove the double marginalization problem. In all, we claim that passive backwards integration should indeed be of concern to competition authorities.

The present analysis is related to Chen (2001) who, in a similar setting, investigates the effects of a full vertical merger. For such a merger to increase downstream prices, the unintegrated downstream rival needs to incur costs of switching between upstream suppliers. These switching costs allow the integrated firm to charge the downstream competitor an input price higher than that charged by the next efficient upstream supplier.

We show that for all downstream prices to increase, neither full vertical integration nor switching costs are necessary, nor does the input price charged to independent downstream firms need to increase. Indeed, partial backwards integration without the transfer of control rights is effective in raising consumer prices when full integration is not, i.e. when the Chicago argument about the efficiency increasing effect of vertical mergers does hold. The reason is that with passive ownership, only profit claims are transferred to downstream firms, but not control on upstream prices. In consequence, downstream firms can acquire profit claims of suppliers to relax downstream competition.

Separating control from ownership in order to relax competition is the general theme in the literature on strategic delegation. While that term was coined by Fershtman et al. (1991), our result is most closely related to the earlier example provided by Bonanno and Vickers (1988), where manufacturers maintain profit claims in their retailers through

\footnotetext{
${ }^{4}$ Flath (1989) shows that with successive Cournot oligopolies, constant elasticity demand and symmetric passive ownership, these two effects cancel out, so in his model, pure passive backwards integration has no effect. Greenlee and Raskovich (2006) confirm this invariance result for equilibria involving an upstream monopoly and symmetric downstream firms under competition in both, price and quantity. These invariance results suggest that there is no need for competition policy to address passive vertical ownership. By contrast, we show that the invariance property of downstream prices does not apply within a more general industry structure involving upstream asymmetric Bertrand competition, where the upstream firms are characterized by differing efficiency levels in production.
} 
two-part tariffs, but delegate the control over retail prices, in order to induce a softer price setting of the competitor. In the present case, strategic delegation involves backwards oriented activities. The particular twist added to that literature is that the very instrument firms used to acquire control is used short of implementing it.

The competition dampening effect identified in the present paper relies on internalizing rivals' sales through a common efficient supplier. This relates to the common agency argument of Bernheim and Whinston (1985). Strategic complementarity is essential in the sense that rivals need to respond with price increases to the raider's incentive to increase price. Indeed, acquiring passive vertical ownership is a fat cat strategy, in the terms coined by Fudenberg and Tirole (1984).

A different kind of explanation for backward integration without control is that transferring residual profit rights can mitigate agency problems, for example when firm specific investments are decided upon under incomplete information (Riordan, 1991; Dasgupta and Tao, 2000). Güth et al. (2007) analyze a model of vertical cross share holding to reduce informational asymmetries, and provide experimental evidence. ${ }^{5}$ While such potentially desirable effects of partial vertical ownership should be taken into account within competition policy considerations, we abstract from them for expositional clarity.

The remainder of this article is structured as follows: We introduce the model in Section 2. In Section 3, we solve and characterize the 3rd stage downstream pricing subgame. In Section 4, we solve for, and characterize the equilibrium upstream prices arising in Stage 2. In Section 5, we analyze a key element involved in the solution to the first stage of the game, namely the profitability of partial acquisitions. In the Extension Section 6 , we first compare the results derived in the baseline model with those derived under full vertical integration. Second, we touch at the case in which upstream competition is ineffective, so the efficient firm can exercise complete monopoly power. ${ }^{6}$ Third, we look at the effects of bans on upstream price discrimination common to many competition policy prescriptions. Fourth and fifth, we consider the effects of relaxing structural assumptions: We replace sequential by simultaneous pricing decisions, and then allow the upstream firms to charge two-part, rather than linear tariffs. The results remain unchanged. This is surprising in particular, since two part tariffs are considered to remove inefficiencies due to double marginalization. We conclude with Section 7. All relevant proofs are removed to an appendix.

\section{Model}

Two symmetric downstream firms $i, i \in\{A . B\}$ competing in prices $p_{i}$ produce and sell imperfect substitutes obeying demands $q_{i}\left(p_{i}, p_{-i}\right)$ that satisfy

Assumption 1. $\infty>-\frac{\partial q_{i}\left(p_{i}, p_{-i}\right)}{\partial p_{i}}>\frac{\partial q_{i}\left(p_{i}, p_{-i}\right)}{\partial p_{-i}}>0$ (product substitutability).

\footnotetext{
${ }^{5}$ Höffler and Kranz (2011a,b) investigate how to restructure former integrated network monopolists. They find that passive ownership of the upstream bottleneck (legal unbundling) may be optimal in terms of downstream prices, upstream investment incentives and prevention of foreclosure. However, a key difference to our setting is that they keep upstream prices exogenous.

${ }^{6}$ In a companion paper (Hunold et al., 2011), we focus on ineffective competition and compare the effects of passive and controlling partial backward and forward integration.
} 
The production of one unit of downstream output requires one unit of a homogenous input produced by two suppliers $j \in\{U, V\}$ with marginal $\operatorname{costs} c^{j}$, who again compete in prices. Assume that $c^{U} \equiv 0$ and $c^{V} \equiv c>0$, so that firm $U$ is more efficient than firm $V$, and $c$ quantifies the difference in marginal costs between $U$ and its less efficient competitor. ${ }^{7}$ All other production costs are normalized to zero. Upstream suppliers are free to price discriminate between the downstream firms. Let $x_{i}^{j}$ denote the quantities firm $i$ buys from supplier $j$, and $w_{i}^{j}$ the associated linear unit price charged by supplier $j$. Finally, let $\delta_{i}^{j} \in[0, \bar{\delta}], 0<\bar{\delta} \leq 1$, denote the ownership share downstream firm $i$ acquires in upstream firm $j$. Information is assumed to be perfect. The game has three stages:

1. Downstream firms $A$ and $B$ simultaneously acquire ownership shares $\delta_{i}^{j}$ of suppliers.

2. Suppliers simultaneously set sales prices $w_{i}^{j}$.

3. Downstream firms simultaneously buy input quantities $x_{i}^{j}$ from suppliers, produce quantities $q_{i}^{j}$, and sell them at prices $p_{i}$.

Underlying the sequencing is the assumption that ownership is less flexible than prices are, and also easily observable by industry insiders. This is crucial as in the following we employ subgame perfection to analyze how (pure cash flow) ownership affects prices. The assumption that suppliers can commit to upstream prices before downstream prices are set is inessential here.

Upstream supplier $j$ 's profit is given by

$$
\pi^{j}=\sum_{i \in\{A, B\}}\left(w_{i}^{j}-c^{j}\right) x_{i}^{j}
$$

Downstream firm $i$ 's profit, including the return from the shares held in upstream firms, is

$$
\Pi_{i}=\underbrace{p_{i} q_{i}\left(p_{i}, p_{-i}\right)-\sum_{j \in\{U, V\}} w_{i}^{j} x_{i}^{j}}_{\text {operational profit }}+\underbrace{\sum_{j \in\{U, V\}} \delta_{i}^{j} \pi^{j},}_{\text {upstream profit shares }}
$$

to be maximized with respect to its own price $p_{i}$, subject to the constraint $\sum x_{i}^{j} \geq q_{i}$, so that input purchases are sufficient to satisfy quantity demanded.

We use the term partial ownership for an ownership share strictly between zero and one. We call passive an ownership share that does not involve control over the target firm's pricing strategy, and active one that does. The possibility to control the target's instruments is treated as independent of the ownership share in the target. With this we want to avoid the discussion of at which level of shareholdings control arises. That depends on institutional detail and the distribution of ownership share holdings in the target firm. Although a restriction of $\bar{\delta}<1 / 2$ appears highly plausible for ownership to be passive, our results on passive ownership hold for any $\bar{\delta}<1$. See O'Brien and Salop (1999), as well as Hunold, Röller and Stahl (2011) for a discussion of this issue. Finally, we define an allocation to involve effective (upstream) competition, if the efficient upstream

\footnotetext{
${ }^{7}$ The restriction to two downstream and two upstream firms is without loss of generality, as long as the upstream firms can be ordered by degree of efficiency.
} 
firm is constrained in its pricing decision by its upstream competitor, i.e. can charge effective unit input prices, as perceived by downstream firms, no higher than $c$.

An equilibrium in the third, downstream pricing stage is defined by downstream prices $p_{A}^{*}$ and $p_{B}^{*}$ as functions of the upstream prices $w_{i}^{j}$ and ownership shares $\delta_{i}^{j}, i \in\{A, B\} ; j \in$ $\{U, V\}$ held by the downstream in the upstream firms, subject to the condition that upstream supply satisfies downstream equilibrium quantities demanded. In order to characterize that equilibrium, it is helpful to impose the following conditions on the profit functions:

Assumption 2. $\frac{\partial^{2} \Pi_{i}\left(p_{i}, p_{-i}\right)}{\left(\partial p_{i}\right)^{2}}<0$ (concavity)

Assumption 3. $\frac{\partial^{2} \Pi_{i}\left(p_{i}, p_{-i}\right)}{\partial p_{i} \partial p_{-i}}>0$ (strategic complementarity)

Assumption 4. $\frac{\partial^{2} \Pi_{i}\left(p_{i}, p_{-i}\right)}{\partial p_{i} \partial p_{-i}} / \frac{\partial^{2} \Pi_{i}\left(p_{i}, p_{-i}\right)}{\partial p_{i} \partial p_{i}}>\frac{\partial^{2} \Pi_{-i}\left(p_{-i}, p_{i}\right)}{\partial p_{-i} \partial p_{-i}} / \frac{\partial^{2} \Pi_{-i}\left(p_{-i}, p_{i}\right)}{\partial p_{-i} \partial p_{i}}(\text { stability })^{8}$

An equilibrium in the second, upstream pricing stage specifies prices $w_{i}^{j *}$ conditional on ownership shares $\delta_{i}^{j}, i \in\{A, B\} ; j \in\{U, V\}$.

We sometimes wish to obtain closed form solutions for the complete game. Towards those we use the linear demand specification

$$
q_{i}\left(p_{i}, p_{-i}\right)=\frac{1}{(1+\gamma)}\left(1-\frac{1}{(1-\gamma)} p_{i}+\frac{\gamma}{(1-\gamma)} p_{-i}\right), 0<\gamma<1,
$$

with $\gamma$ quantifying the degree of substitutability between the downstream products. With this demand specification, Assumptions 1 to 4 are satisfied.

\section{Stage 3: Supplier choice and the determination of downstream prices}

Downstream firm $i$ 's cost of buying a unit of input from supplier $j$ in which it holds $\delta_{i}^{j}$ shares is obtained by differentiating the downstream profit in (2) with respect to the input quantity $x_{i}^{j}$, i.e.

$$
\frac{\partial \Pi_{i}}{\partial x_{i}^{j}}=-\underbrace{w_{i}^{j}}_{\text {unit price }}+\underbrace{\delta_{i}^{j}\left(w_{i}^{j}-c^{j}\right)}_{\text {upstream profit increase }} .
$$

Thus, the unit input price $w_{i}^{j}$ faced by downstream firm $i$ is reduced by the contribution of that purchase to supplier $j$ 's profits. Call $-\frac{\partial \Pi_{i}}{\partial x_{i}^{j}}$ the effective input price downstream firm $i$ is confronted with when purchasing from firm $j$. The minimal effective input price for downstream firm $i$ is given by

$$
w_{i}^{e} \equiv \min \left\{w_{i}^{U}\left(1-\delta_{i}^{U}\right), w_{i}^{V}\left(1-\delta_{i}^{V}\right)+\delta_{i}^{V} c\right\}
$$

\footnotetext{
${ }^{8}$ The stability assumption implies that the best-reply function of $i$ plotted in a $\left(p_{i}, p_{-i}\right)$ diagram is flatter than the best-reply function of $-i$ for any $p_{-i}$, implying that an intersection of the best reply functions is unique.
} 
As natural in this context, firm $i$ buys from the upstream supplier $j$ offering the minimal effective input price. If both suppliers charge the same effective input price, we assume that $i$ buys all inputs from the efficient supplier $U$ as that supplier could slightly undercut to make its offer strictly preferable. Let $j(-i)$ denote the supplier $j$ from which the other downstream firm $-i$ buys its inputs. Differentiating downstream profits with respect to the own downstream price yields the two first order conditions

$$
\begin{gathered}
\frac{\partial \prod_{i}}{\partial p_{i}}=\left(p_{i}-w_{i}^{e}\right) \frac{\partial q_{i}\left(p_{i}, p_{-i}\right)}{\partial p_{i}}+q_{i}\left(p_{i}, p_{-i}\right)+\delta_{i}^{j(-i)}\left(w_{-i}^{j(-i)}-c^{j(-i)}\right) \frac{\partial q_{-i}\left(p_{-i}, p_{i}\right)}{\partial p_{i}}=0 \\
i \in\{A, B\} .
\end{gathered}
$$

Observe that whenever $\delta_{i}^{j(-i)}>0$, downstream firm $i$ takes into account that changing its sales price affects the upstream profits earned not only via sales quantities $q_{i}$ to itself, but also via sales quantities $q_{-i}$ to its competitor.

By Assumptions 1-4, the equilibrium of the downstream pricing game is unique, stable and fully characterized by the two first order conditions for given unit input prices and ownership shares $0 \leq \delta_{i}^{j} \leq \bar{\delta}$. Note that strategic complementarity holds under the assumption of product substitutability if margins are non-negative and $\frac{\partial^{2} q_{-i}}{\partial p_{i} \partial p_{-i}}$ is not too negative (cf. Equation (5)). Also observe that if prices are strategic complements at $\delta_{A}=\delta_{B}=0$, then strategic complementarity continues to hold for small partial ownership shares.

\section{Stage 2: Determination of upstream prices under passive partial ownership}

$V$ cannot profitably sell at a (linear) price below its marginal production $\operatorname{cost} c$. $U$ as the more efficient supplier can profitably undercut $V$ at any positive upstream price. This implies that, in equilibrium, $U$ supplies both downstream firms, and this at effective prices at most as high as $c .{ }^{9}$ To simplify notation, let henceforth $\delta_{i} \equiv \delta_{i}^{U}$ and $w_{i} \equiv w_{i}^{U}$. Let $p_{i}^{*}\left(w_{i}, w_{-i} \mid \delta_{A}, \delta_{B}\right)$ denote the equilibrium prices of the downstream subgame as a function of input prices. Formally, $U^{\prime} s$ problem is

$$
\max _{w_{A}, w_{B}} \pi^{U}=\sum_{i=A, B} w_{i} q_{i}\left(p_{i}^{*}\left(w_{i}, w_{-i} \mid \delta_{A}, \delta_{B}\right), p_{-i}^{*}\left(w_{-i}, w_{i} \mid \delta_{A}, \delta_{B}\right)\right)
$$

subject to the constraints $w_{i}\left(1-\delta_{i}\right) \leq c, i \in\{A, B\}$ such that downstream firms are willing to source from $U$. Differentiating the reduced-form profit in (6) with respect to $w_{i}$ yields

$$
\frac{d \pi^{U}}{d w_{i}}=q_{i}\left(p_{i}^{*}, p_{-i}^{*}\right)+w_{i} \frac{d q_{i}\left(p_{i}^{*}, p_{-i}^{*}\right)}{d w_{i}}+w_{-i} \frac{d q_{-i}\left(p_{-i}^{*}, p_{i}^{*}\right)}{d w_{i}} .
$$

Starting at $w_{i}=w_{-i}=0$, it must be profit increasing for $U$ to marginally increase upstream prices, because both $q_{i}>0$ and $q_{-i}>0$. By continuity and boundedness of the derivatives, this remains true for small positive upstream prices. Hence the constraints

\footnotetext{
${ }^{9}$ Another obvious implication is that none of the downstream firms has an interest in obtaining passive shares from the unprofitable upstream firm $V$.
} 
are strictly binding for any partial ownership structure, so there is effective upstream competition, if $c$ is sufficiently small. In this case, equilibrium upstream prices are given by

$$
w_{i}^{*}=c /\left(1-\delta_{i}\right)
$$

We assume this regime to hold in the core part of the paper. ${ }^{10}$ In this regime, $U$ 's profits are uniquely given by

$$
\pi^{U}=\frac{c}{\left(1-\delta_{A}\right)} q_{A}\left(p_{A}^{*}, p_{B}^{*}\right)+\frac{c}{\left(1-\delta_{B}\right)} q_{B}\left(p_{B}^{*}, p_{A}^{*}\right)
$$

and $V$ 's profits are zero. We summarize in

Lemma 1. The efficient upstream firm $U$ supplies both downstream firms at any given passive partial backwards ownership shares $\left(\delta_{A}, \delta_{B}\right)$. Under effective competition, i.e. for sufficiently small $c, U$ charges prices $w_{i}^{*}=c /\left(1-\delta_{i}\right), i \in\{A, B\}$, so that the effective input prices are equal to the marginal cost $c$ of the less efficient supplier $V$.

With these upstream prices, downstream profits reduce to

$$
\Pi_{i}=\left(p_{i}-c\right) q_{i}\left(p_{i}, p_{-i}\right)+\delta_{i} \frac{c}{1-\delta_{-i}} q_{-i}\left(p_{-i}, p_{i}\right)
$$

Observe that if firm $i$ holds shares in firm $U$ so that $\delta_{i}>0$, its profit $\Pi_{i}$, via its upstream holding, increases in the quantity demanded of its rival's product $q_{-i}$. All else given, this provides for an incentive to raise the price for its own product. Formally, firm i's marginal profit

$$
\frac{\partial \Pi_{i}}{\partial p_{i}}=q_{i}\left(p_{i}, p_{-i}\right)+\left(p_{i}-c\right) \frac{\partial q_{i}}{\partial p_{i}}+\delta_{i} \frac{c}{1-\delta_{-i}} \frac{\partial q_{-i}}{\partial p_{i}}
$$

increases in $\delta_{i}$. Also, if $\delta_{i}>0$, the marginal profit of $i$ increases in $\delta_{-i}$, as this increases the upstream margin earned on the product of $-i$. Finally, since $\frac{\partial q_{-i}}{\partial p_{i}}$ increases when the products $(i,-i)$ become closer substitutes, the external effect internalized via the cash flow right $\delta_{i}$ becomes stronger, and with it the effect on equilibrium prices. In all, this yields the following central result:

Proposition 1. Let Assumptions 1-4 hold and upstream competition be effective. Then

(i) both equilibrium downstream prices $p_{i}^{*}$ and $p_{-i}^{*}$ increase in both $\delta_{i}$ and $\delta_{-i}$ for any non-controlling ownership structure

(ii) the increase is stronger when the downstream products are closer substitutes.

Corollary 1. Any increase in passive ownership in $U$ by one or both downstream firms is strictly anti-competitive.

Proposition 1 is illustrated in Figure 1 for the case $\delta_{A}>\delta_{B}=0$. The solid line is the inverted best-reply function $p_{B}^{r}\left(p_{A}\right)^{-1}$ of $B$ at a given $\delta_{A}>0$. The dashed line is $A^{\prime} s$ best reply $p_{A}^{r}\left(p_{B}\right)$ for $\delta_{A}=0$, and the dashed-dotted line above this is $A^{\prime} s$ best reply

\footnotetext{
${ }^{10}$ Clearly, if $\pi^{U}\left(w_{A}, w_{B}\right)$ is concave, both (one) of the constraints do(es) not bind for $c$ sufficiently large, in which case $U$ can charge both (one) downstream firm(s) the unconstrained monopoly prices below $c$.
} 


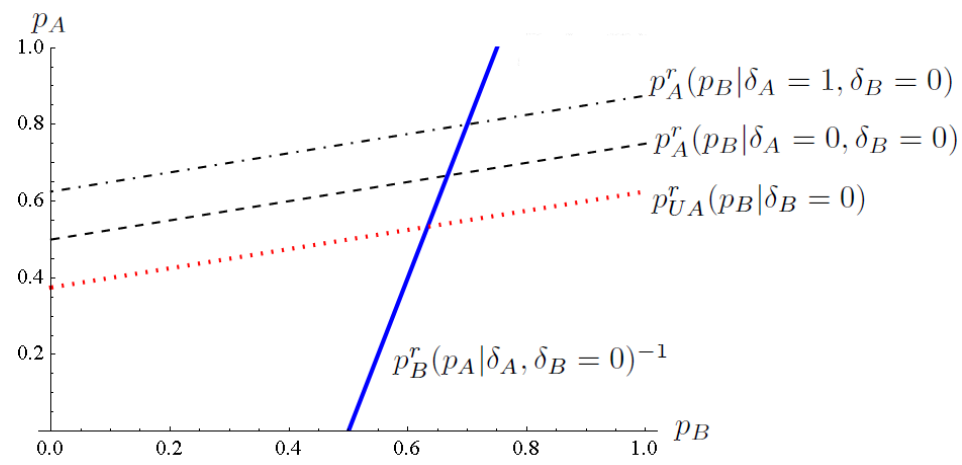

Figure 1: Best-reply functions of downstream firms $A, B$ and the vertically integrated unit $U A$ for linear demand as in (3), with $\gamma=0.5$ and $c=0.5$.

for $\delta_{A}=1$. Hence, choosing $\delta_{A}$ amounts to choosing the best-reply function $p_{A}^{r}\left(p_{B}\right)$ in the subsequent pricing game. This becomes central when analyzing the profitability of acquisitions in the next section.

\section{Stage 1: Acquisition of shares by downstream firms}

In this section, we assess the profitability of backward acquisitions in form of passive stakes by downstream firms in upstream firms. We restrict our attention to the acquisition of stakes in firm $U$. This is easily justifiable within the context of our model: Since both downstream firms decide to acquire input from the more efficient firm, the less efficient firm $V$ does not earn positive profits in equilibrium. Hence, there is no scope for downstream firms to acquire passive interests in $V$.

Rather than specifying how bargaining about ownership stakes takes place and conditioning the outcome on the bargaining process, we determine the central incentive condition for backwards acquisitions to materialize, namely that there are gains from trading claims to profits in $U$ between that upstream firm and one of the downstream firms.

In order to enhance intuition, fix for the moment stakes held by firm $B$ at $\delta_{B}=0$. Gains from trading stakes between $A$ and $U$ arise if the the joint profit of $A$ and $U$,

$$
\Pi_{A}^{U}\left(\delta_{A} \mid \delta_{B}=0\right) \equiv\left(1-\delta_{A}\right) \pi^{U}+\Pi_{A}=p_{A}^{*} q_{A}^{*}+c q_{B}^{*}
$$

is higher at some $\delta_{A} \in(0, \bar{\delta}]$ than at $\delta_{A}=0$, where $p_{A}^{*}, q_{A}^{*}$ and $q_{B}^{*}$ all are functions of $\delta_{A}$. The drastic simplification of this expression results from the obvious fact that a positive $\delta_{A}$ just redistributes profits between $A$ and $U$. The gains from trade between $A$ and $U$ can thus arise only via indirect effects on prices and quantities induced by increases in $\delta_{A}$. Why should there be such gains from trade at all?

The vertical effects of an increase in $\delta_{A}$ between $A$ and $U$ are exactly compensating. All that changes are $A$ 's marginal profits. They increase, because with an increasing $\delta_{A}$ an increasing share of $U$ 's sales to $B$ is internalized. This leads $A$ to increase $p_{A}$, which in turn induces $B$ to increase $p_{B}$. That price increase is not only profitable to $B$, but eventually yields a net benefit to $A$ and $U$. Intuition suggests that this competition softening effect is profitable to the profits of $U$ and $i$ if competition is fierce, i.e. $c$ is sufficiently small. Indeed, evaluating $d \Pi_{A}^{U} / d \delta_{A}$ at small $c$ yields 
Proposition 2. Increasing partial passive ownership stakes of firm $i$ firm in firm $U$ increase the combined profits of $i$ and $U$, if upstream competition is sufficiently intense.

This argument continues to hold for trades in upstream ownership shares involving both downstream firms, under the obvious restriction that control is not transferred from $U$ to any one of the downstream firms. ${ }^{11}$

Corollary 2. Increasing partial passive ownership stakes of firms $i$ and $-i$ in firm $U$ increases the industry profit $\Pi_{A B}^{U} \equiv p_{A}^{*} q_{A}^{*}+p_{B}^{*} q_{B}^{*}$, if upstream competition is sufficiently intense.

Using the linear demand example introduced in (3), we can make explicit how our case assumption that upstream competition is intense enough relates to the intensity of downstream competition, and in addition derive optimal shareholdings by the downstream firms. The joint profits of firms $i$ and $U$ are maximized at a positive passive ownership share $\delta_{i}$, given $\delta_{-i}=0$, if $c<\gamma^{2} / 4$. Recall that a large $\gamma$ corresponds to strong competition downstream, and a small $c$ to strong competition upstream. Hence if overall competition is strong, it is profitable to acquire passive ownership as this increases downstream prices. Since the upper bound monotonically increases in $\gamma$, the range of $c$ in which this result holds increases in $\gamma$. At any rate, under this condition, the ownership share maximizing $\Pi_{i}^{U}$ is given by

$$
\left.\delta_{i}^{*}\right|_{\delta_{-i}=0}=\min \left(\frac{4 c \gamma(1+\gamma)+\gamma^{2}\left(2-\gamma-\gamma^{2}\right)-8 c}{4 c \gamma\left(2-\gamma^{2}\right)}, \bar{\delta}\right) .
$$

Since a firm's backwards interests confer a positive externality on the second firm's profits, the industry profits $p_{A}^{*} q_{A}^{*}+p_{B}^{*} q_{B}^{*}$ are maximized at positive passive ownership shares if the less restrictive condition $c<\gamma / 2$ holds. ${ }^{12}$ Under this condition, the industry profit is maximized at

$$
\delta_{A}^{*}=\delta_{B}^{*}=\min \left(\frac{\gamma-2 c}{\gamma-2 c+2 c \gamma}, \bar{\delta}\right)
$$

with the natural restriction that $\bar{\delta} \leq 1 / 2$.

\section{$6 \quad$ Extensions}

\subsection{Effects of control}

In this extension, we compare the effects of passive partial backwards integration with those generated by full vertical integration (i.e. a vertical merger) between one of the downstream firms, say $A$, and the efficient upstream firm $U$. We first consider full vertical integration.

Let the ownership structure under vertical integration be described by $\left\{\delta_{A}=1, \delta_{B}=\right.$ $0\}$, and let $A$ control $U^{\prime} s$ pricing decisions. Since $U$ is more efficient than $V$, the vertically

\footnotetext{
${ }^{11}$ In Subsection 6.1, we consider the effect of a transfer of control, and compare the outcome with the present one.

${ }^{12}$ Observe that $\gamma^{2} / 4<\gamma / 2$. This indicates the internalization of the positive externality on the downstream competitor when interests in the efficient upstream firm are acquired to maximize industry profits .
} 
integrated firm continues to meet any positive price $w_{B}^{V}$ charged by $V$. Under effective upstream competition, it is again optimal to set $w_{B}^{U}=c$. By contrast, $A$, within the vertically integrated firm, takes account of the true input cost normalized to zero. ${ }^{13}$

Consider now the effect of vertical integration on downstream prices. Still faced with marginal input costs of $c$, vertical integration does not change the best response function of $B$. However, vertical integration has two countervailing effects on the setting of $p_{A}$. Upward price pressure arises because the integrated unit fully internalizes the upstream profit from selling to firm $B$, that is $c q_{B}\left(p_{B}, p_{A}\right)$. Conversely, downward price pressure arises because double marginalization on product $A$ is eliminated, as the downstream costs, $c q_{A}\left(p_{A}, p_{B}\right)$ under separation, are decreased to zero. Indeed, it can be shown that the downward pressure is stronger, yielding

Proposition 3. Under Assumptions 1 to 4, a vertical merger between one downstream firm and $U$ decreases both downstream prices, as compared to complete separation.

As another consequence, observe that foreclosure does not arise under vertical integration.

Returning to Figure 1, note that for any $\delta_{A}>0$, the best response of the merged entity, $p_{U A}^{r}\left(p_{B}\right)$, represented by the dotted line in Figure 1, is located below the one arising under separation.

Proposition 3 is also contained in Chen (2001). Yet for an anti-competitive increase in downstream prices to occur in that model, Chen needs to assume that $B$ has to make supplier specific investments to buy from $U$, such that the integrated firm can set $w_{B}^{U}>c$, and still continue to be the exclusive supplier of $B$. By contrast, as we state in Proposition 1, downstream prices increase even without switching costs, once we allow for the separation of profit claims and control of the target. Summarizing:

Corollary 3. Under Assumptions 1 to 4 and effective upstream competition, a vertical merger between one of the downstream firms and the efficient upstream firm leads to a decrease of all downstream prices when compared to those arising under vertical separation, whence any passive partial backwards ownership of one or both downstream firms in the efficient supplier $U$ leads to an increase in all downstream prices.

We now turn to a comparison of the combined profits of $A$ and $U$ under full vertical separation and full integration. By Proposition 3, vertical integration decreases both downstream prices. This is not necessarily desirable for $A$ and $U$ when the overall margins earned under vertical separation are below the industry profit maximizing level. In order to assess whether separation increases the combined profits $\Pi_{A}^{U}$, we ask the following question: Starting at vertical separation, is it profitable to move towards integration? Indeed, it can be shown that this is initially strictly unprofitable for $c$ sufficiently small. By continuity, there exists an interval $(0, \bar{c}]$ such that for any $c$ in this interval vertical separation is more profitable than integration. Hence

Lemma 2. Complete vertical separation of $A$ and $U$ is more profitable than a merger between $A$ and $U$ if upstream competition is sufficiently intense.

\footnotetext{
${ }^{13}$ In line with the literature - examples are Bonanno and Vickers (1988) or Chen (2001) - we assume here that under vertical integration, the upstream firm is unable to commit to an internal transfer price to the vertically integrated downstream firm that is higher than its true marginal cost.
} 
Combining Proposition 2 and Lemma 2 yields

Corollary 4. Passive partial backwards integration of firm i into firm U leads to higher profits than vertical integration, if upstream competition is sufficiently intense. Then, downstream firms have the incentive to acquire maximal backwards interests, short of controlling the upstream firm $U$.

As emphasized before, this result is nicely related to the literature on strategic delegation. The particular twist here is that the very instrument intended to acquire control, namely the acquisition of equity in the target firm, is employed short of controlling the target. While this benefits the industry, it harms consumer welfare.

\subsection{Ineffective competition}

In the baseline model, we have emphasized the effects of passive partial backwards integration when there is effective upstream competition, as generated by a sufficiently small difference $c$ in marginal costs between the efficient firm $U$ and the less efficient firm $V$ such that $U$ was constrained by $V$. We now sketch the case where $c$ is large such that $U$ can behave as an unconstrained upstream monopolist.

As before, an increase in $\delta_{i}$, the passive backwards ownership share in the supplier, softens the acquiring downstream firm $i$ 's best response to increases in the input price, as the effective input price decreases in $\delta_{i}$. It also induces the acquiring downstream firm to internalize its rivals' sales which leads to an increase in the acquiring firm's downstream price. The first effect dominates, so that downstream prices decrease in $\delta_{i}$ for given (nominal) input prices. As $U$ is unconstrained, it can increase $w_{i}$ until its marginal profits are zero again. With this, both effects of an increase in $\delta_{i}$ on downstream prices are internalized through the upstream monopolist's first order conditions.

For symmetric passive ownership by downstream firms, Greenlee and Raskovich (2006) show that in this case upstream and downstream price adjustments exactly compensate, so downstream prices stay the same independent of the magnitude of partial ownership and the intensity of downstream competition. We can show that the incentive of a downstream firm to passive backwards integration is lost if $U$ can price discriminate. See Hunold et al. (2011) for a further discussion.

By contrast, with effective upstream competition, only the first, marginal cost decreasing effect of an increase in $\delta_{i}$ is counterbalanced by the efficient upstream firm $U$, and that perfectly. Hence with effective upstream competition, the overall effect equals the second effect of internalizing rivals' sales, and thus both downstream prices increase in $\delta_{i}$.

\subsection{Non-discriminatory upstream prices}

Many competition laws require a firm to charge non-discriminatory prices. While by the U.S. Robinson-Patman Act, non-discrimination is a widely applied rule, Article 102 of the Treaty on the Functioning of the European Union restricts the application of the rule to dominant firms.

Clearly, under effective competition, symmetric passive ownership with $\delta_{A}=\delta_{B}>0$ may arise as an equilibrium. Here, supplier $U$ has no incentive to price discriminate. 
Yet, as we have shown in Proposition 1, symmetric passive ownership is clearly anticompetitive, so in this case, a non-discrimination rule has no effect at all, and in particular no pro-competitive effect.

Consider instead one of the firms', say $A$ 's, incentive to acquire a backwards interest in firm $U$ when non-discrimination is effective and $\delta_{B}=0$. Then $U$ must charge a uniform price $c$ if it wants to serve both downstream firms. This yields profits to $A$ of

$$
\Pi_{A}=\left(p_{A}-c\right) \cdot q_{A}+\delta_{A} c \cdot\left(q_{A}+q_{B}\right)
$$

Differentiating with respect to $p_{A}$ and $\delta_{A}$ yields

$$
\frac{\partial^{2} \Pi_{A}}{\partial p_{A} \partial \delta_{A}}=c \cdot\left[\frac{\partial q_{A}\left(p_{A}, p_{B}\right)}{\partial p_{A}}+\frac{\partial q_{B}\left(p_{B}, p_{A}\right)}{\partial p_{A}}\right] .
$$

By Assumption 1, the own price effect dominates the cross price effect, and therefore the cross derivative in (12) is negative if $\frac{\partial q_{B}\left(p_{B}, p_{A}\right)}{\partial p_{A}} \leq \frac{\partial q_{A}\left(p_{A}, p_{B}\right)}{\partial p_{B}}$. At $\delta_{A}=0$, the equality $p_{A}=p_{B}$ implies that $\frac{\partial q_{B}}{\partial p_{A}}=\frac{\partial q_{A}}{\partial p_{B}}$. Thus increasing $\delta_{A}$ decreases the marginal profit of $A$. Hence, the best reply $p_{A}^{r}\left(p_{B} \mid \delta_{A}\right)$ and, in consequence, both equilibrium downstream prices, decrease in $\delta_{A}$ at $\delta_{A}=0$. By continuity, this holds for small positive $\delta_{A}$. This result generalizes to all feasible $\delta_{A}$ as long as $\frac{\partial q_{B}}{\partial p_{A}} \leq \frac{\partial q_{A}}{\partial p_{B}}$ for $p_{A}<p_{B}$, e.g. in case of linear demand. Under this condition, if only one downstream firm has passive ownership in $U$, and $U$ optimally serves both downstream firms, then such ownership is not anticompetitive under a non-discrimination rule. ${ }^{14}$

\subsection{Simultaneous price setting}

So far, we have assumed that upstream prices are set before downstream prices. Consider now that all prices are set simultaneously. In this situation, upstream firms take downstream prices as given. For $U$, increasing effective prices up to $c$ does not affect quantity. Hence, effective equilibrium upstream prices must be equal to $c$. However, with simultaneous price setting, an equilibrium does only exist as long as the participation constraints of downstream firms are not violated at effective upstream prices of $c$.

Lemma 3. Under effective competition, sequential and simultaneous setting of up-and downstream prices are outcome equivalent.

Note that as long as the participation constraints of downstream firms do not bind, the simultaneous price setting is equivalent to the case in which downstream prices are set first, followed by upstream prices and, finally, downstream firms choose where to buy inputs.

\footnotetext{
${ }^{14} U$ wants to serve both downstream firms for a small $\delta_{i}$, given $\delta_{-i}=0$. Once $\delta_{i}$ becomes large, $U$ may find it profitable to set a high nominal price at which only $i$ wants to purchase. This makes $-i$ dependent on $V$. In turn, $V$ can raise the price charged to $-i$ above $c$, yielding partial foreclosure. However, it is unclear whether partial foreclosure is an equilibrium. In a forthcoming paper, we will discuss in detail the effects of non-discrimination rules in the different case situations.
} 


\subsection{Two-part tariffs}

The assumption of linear upstream prices is clearly restrictive, as argued already in Tirole (1988). One is tempted to argue that if the upstream firms would be allowed to offer contracts from a more general pricing regime, such as two part tariffs, double marginalization would be removed, and with it the anti-competitive effect of passive partial backwards integration discussed here. We show, however, that under vertical separation, as long as competition is sufficiently strong, the efficient firm does optimally charge a linear tariff even if a two-part tariff is admissible. This result extends naturally into passive backwards ownership in the efficient supplier. Therefore, backwards ownership leads to increases in downstream prices harming consumer welfare even when two-part tariffs are admitted.

We start from complete vertical separation, so $\delta_{A}=\delta_{B}=0$, and maintain the assumption that tariff offers are non-exclusive; that all contract offers are observable to all downstream firms upon acceptance, and that acceptance decisions are observable when downstream prices are set. A tariff offered by supplier $j$ to downstream firm $i$ is summarized by $\left\{f_{i}^{j}, w_{i}^{j}\right\}$, where $f_{i}^{j}$ is the fixed fee downstream firm $i$ has to pay the upstream firm $j$ upon acceptance of the contract, and $w_{i}^{j}$ continues to be the marginal input price. Denote by $\pi_{i}^{*}\left(w_{i}^{j}, w_{-i}^{k}\right), j, k \in\{U, V\}$ firm $i$ 's reduced form downstream profits as a function of the marginal input price relevant for each downstream firm, but net of any fixed payment. With the model constructed as in the main part of the paper, the Bertrand logic still holds: $U$ can still always profitably undercut any (undominated) offer by $V$, so in equilibrium $U$ exclusively supplies both downstream firms. Yet if upstream competition is effective, $U$ is restricted by $V$ in its price setting. We require that $V$ 's offers, if accepted, yield it non-negative profits.

It strikes us as helpful to consider the two extreme cases of downstream competition, before moving to the relevant intermediate case. Let downstream firms' demands first be independent. In this case, there are no contracting externalities downstream, i.e. a contract offer by $j \in\{U, V\}$ to $i$ has no effect on $-i$. Against the efficient supplier $U$, the best its competitor $V$ can do is to offer the zero profit tariff $\left(f_{i}^{V}, w_{i}^{V}\right)$ that maximizes the typical downstream firm $i$ 's profit. This is tantamount to maximizing firm $i$ 's profit subject to the the constraint $f_{i}^{V}=x_{i}\left(p_{i}\left(w_{i}^{V}\right)\right)\left(c-w_{i}^{V}\right)$, where $x_{i}\left(p_{i}\left(w_{i}^{V}\right)\right)$ is the quantity procured by downstream firm $i$ given the tariff proposed by upstream firm $V$.

Inserting $V$ 's zero profit constraint and equating input demand and supply, so $x_{i}=q_{i}$, yields a profit to downstream firm $i$ of $\left(p_{i}^{*}\left(w_{i}^{V}\right)-w_{i}^{V}\right) q_{i}\left(p_{i}^{*}\left(w_{i}^{V}\right)\right)-f_{i}^{V}=\left(p_{i}^{*}\left(w_{i}^{V}\right)-\right.$ $\left.w_{i}^{V}\right) q_{i}\left(p_{i}^{*}\left(w_{i}^{V}\right)\right)-q_{i}\left(p_{i}^{*}\left(w_{i}^{V}\right)\right)\left(c-w_{i}^{V}\right)=\left(p_{i}^{*}\left(w_{i}^{V}\right)-c\right) q_{i}\left(p_{i}^{*}\left(w_{i}^{V}\right)\right)$. Since $V$ wants to offer the best possible alternative to the typical downstream firm, the unique maximizer of that last expression is $w_{i}^{V}=c$. Hence the best offer $V$ can make is $\{0, c\}$. In consequence, if procuring from $V$, downstream firm $i$ would obtain maximal profits $\pi_{i}^{*}(c)=\left(p_{i}^{*}(c)-\right.$ c) $q_{i}\left(p_{i}^{*}(c)\right)$.

What is the best offer $U$ can make against this? Suppose $U$ would match $V$ 's offer by setting $\{0, c\}$. Then $U$ would leave downstream profits unchanged, and obtain $\pi^{U}(0, c)=$ $c q_{i}\left(p_{i}^{*}(c)\right)$ from firm $i$. Suppose alternatively that $U$ would set $w_{i}^{U}=w_{-i}^{U}=0$ implying $p_{i}^{*}=p_{-i}^{*}=p^{M} \equiv \arg \max _{p} p q_{i}(p, p)$, i.e. the monopoly prices that induce the industry profit maximizing outcome. Then, in order to match the profits generated downstream under $V$ 's offer, $U$ must set $f_{i}^{U}=p_{i}^{*}(0) q_{i}\left(p_{i}^{*}(0)\right)-\left(p_{i}^{*}(c)-c\right) q_{i}\left(p_{i}^{*}(c)\right)>c q_{i}\left(p_{i}^{*}(c)\right)$. Hence 
$U$ prefers to set $\left\{f_{i}^{U}, 0\right\}$, with $f_{i}^{U}=p_{i}^{*}(0) q_{i}\left(p_{i}^{*}(0)\right)-\left(p_{i}^{*}(c)-c\right) q_{i}\left(p_{i}^{*}(c)\right)$. In this case the tariff is "extremely nonlinear", and $U$ 's profit opportunities are constrained by $V$ 's downstream profit maximizing zero profit program, that induces downstream profits $\pi_{i}^{*}(c)$ per firm $i$. In a nutshell, when downstream demands are independent, $U$ cannot do better than removing double marginalization by setting the marginal price to zero, and absorbing as much of the downstream firms' profit as admitted by the outside option offered by $V$.

Let now downstream competition be perfect, such that when faced with equal input prices, downstream firms make zero profits. Hence equilibrium downstream prices cannot exceed $c$, the marginal costs which $V$ can offer. For $c<p^{M}$, it is optimal for $U$ to offer contracts with $w_{i}^{U} \leq c, w_{-i}^{U} \geq c$ and $f_{i}^{U}=\left[c-w_{i}^{U}\right] \cdot\left[q_{A}(c, c)+q_{B}(c, c)\right]$. This yields $\pi^{U}=c\left[q_{A}(c, c)+q_{B}(c, c)\right]$ equal to the industry profit.

From all this, we expect that when downstream competition is away from, but close to perfect, the efficient upstream supplier forfeits the possibility to charge a non-linear price and sticks to the maximal linear one. More formally, for given contract offers of $V$ to firm $A$ and $B, U$ 's problem is

$$
\begin{aligned}
\max _{f_{A}^{U}, f_{B}^{U}, w_{A}^{U}, w_{B}^{U}} \pi^{U}= & \sum_{i \in\{A, B\}}\left[w_{i}^{U} q_{i}+f_{i}^{U}\right] \\
\text { s.t. } & \pi_{i}^{*}\left(w_{i}^{U}, w_{-i}^{U}\right)-f_{i}^{U} \geq \pi_{i}^{*}\left(w_{i}^{V}, w_{-i}^{U}\right)-f_{i}^{V} .
\end{aligned}
$$

$U$ has to ensure that an individual deviation of each downstream firm to source from $V$ is not profitable. In equilibrium, the profit constraints of both downstream firms $i \in\{A, B\}$ must be binding, for otherwise $U$ could profitably raise the respective fixed fee $f_{i}^{U}$, until downstream firm $i$ is indifferent between its and $V$ 's contract offer. Note that setting a marginal input price $w_{i}^{U}>c$ with $f_{i}^{U}<0$ can not be an equilibrium. $V$ could profitably offer $\left\{f_{i}^{V}=0, w_{i}^{V} \in\left(c, w_{i}^{U}\right)\right\}$ and thus the downstream firm can accept the offer of $U$ to cash $f_{i}^{U}$ and source at marginal costs of $w_{i}^{V}$. Finally, the equilibrium contract offers made by $V$ must be best replies to $U$ 's equilibrium contract offers. Together with strategic complementarity of the downstream prices, this implies

Lemma 4. If $U$ offers two-part tariffs with $w_{i}^{U} \leq c, i \in\{A, B\}$, then $\{0, c\}$ is $V$ 's unique counteroffer that maximizes a downstream firm's profits and yields $V$ a non-negative profit.

Using these insights and letting $w_{i} \equiv w_{i}^{U}$ and $f_{i} \equiv f_{i}^{U}$ to simplify notation, $U^{\prime} s$ problem reduces to

$$
\max _{w_{A}, w_{B}} \pi^{U}=\sum_{i \in\{A, B\}}\left[w_{i} q_{i}+\pi_{i}^{*}\left(w_{i}, w_{-i}\right)-\pi_{i}^{*}\left(c, w_{-i}\right)\right]
$$

subject to the no-arbitrage constraints $w_{i} \leq c, i \in\{A, B\}$.

Recalling the previous extreme examples with monopolies and perfect competition downstream, one might expect that $U$ 's optimal contract offer is given by $\{0, c\}$, as long as $c$ satisfies $p_{i}^{*}(c, c)<p^{M}$, i.e. the resulting downstream prices are below the industry profit maximizing level. However, lowering $w_{i}$ below $c$ may increase $U$ 's profit even if industry profits decrease. The rationale is that the outside option of downstream firm $i$, i.e. the profit $\pi_{i}^{*}\left(c, w_{-i}\right)$ in case of a deviation to supplier $V$, tends to decline in $i$ 's resulting cost disadvantage $c-w_{-i}$. This disadvantage increases as $w_{-i}$ decreases. In 
turn, $U$ is able to extract more profits through the fixed payment from each downstream firm..$^{15}$

However, we can show that for $c$ sufficiently small, this motive of devaluing the contract partners' outside options is dominated by the incentive to increase double marginalization, yielding the result that upstream tariffs are endogenously linear. This is done in

Proposition 4. If upstream competition is sufficiently intense, then under vertical separation, $\{0, c\}$ is the unique symmetric equilibrium two-part tariff offered by $U$ to both downstream firms.

As before, sufficient intensity of upstream competition is to be seen relative to the intensity of downstream competition. In our linear demand example, it suffices to have $c<\gamma^{2} / 4$. In passing, this is also the condition ensuring the profitability of an initial increase of passive backwards ownership $\delta_{i}$ to $i$ and $U$.

What does change if we allow for passive partial backwards integration? Nothing, we claim. As $\{0, c\}$ is a corner solution, (at least some) passive backwards integration does not change the efficient upstream firm's incentive to charge linear prices even if allowed to charge non-linear ones. Hence

Corollary 5. If upstream competition is sufficiently intense, then also for passive backwards ownership, $\{0, c\}$ is the unique symmetric equilibrium two-part tariff offered by $U$.

As contracts remain linear, Proposition 2 still applies and we obtain

Corollary 6. Even if two-part tariffs are allowed for, partial passive ownership of downstream firm $i$ in supplier $U$ increases bilateral profits $\Pi_{A}^{U}$ and industry profits $\Pi_{A B}^{U}$ compared to complete separation, if upstream competition is sufficiently intense.

Hence the results derived in the main part of the paper for linear tariffs are upheld even if observable two-part tariffs are allowed for and competition is sufficiently intense. When competition is less intense, the tariffs are no more linear, as optimal marginal prices are below $c$ and thus the fixed fee is positive. Yet passive backwards ownership may still be profitable. Calculations with our earlier linear demand example reveal that there exist parameter ranges for which this is the case. A full analysis is beyond the scope of this paper and left for future research.

\section{Conclusion}

In this paper, we consider vertically related markets with differentiated, price setting downstream firms, that produce with inputs from upstream firms supplying a homogenous input at differing marginal costs. We analyze the effect of one or more downstream firms holding passive, that is non-controlling ownership shares in the efficient, and therefore common, supplier. In sharp contrast to related studies, we find that if competition is sufficiently intense, passive ownership leads to increased downstream prices and thus is strictly anti-competitive. Also, passive ownership is anti-competitive where a full vertical

\footnotetext{
${ }^{15}$ For a further discussion of this tradeoff see Sandonis and Fauli-Oller (2006) who focus on Cournot competition with linear demand and do not consider partial ownership.
} 
merger would be pro-competitive. Confronted with the choice between passive backwards integration and a full vertical merger, the firms prefer the former. Hence they voluntarily abstain from controlling the upstream firm, because this would do away with its power to commit to a high industry profit increasing price. The very instrument typically employed to obtain control is used up to the point where control is not attained. This brings an additional feature to the strategic delegation literature.

Our result is driven primarily by a realistic assumption on the upstream market structure, in which an efficient supplier faces less efficient competitors, allowing it to increase upstream prices only when the price increasing effect is absorbed by the downstream firm(s), via their claims on upstream cash flows. We show the result to be robust to changes in other assumptions such as linear upstream prices, and sequential price setting upstream and then downstream. Indeed, once allowing upstream firms to offer two-part tariffs, we find that the equilibrium contracts are endogenously linear if competition is sufficiently intense. Interestingly enough, under effective upstream competition, passive ownership in suppliers tends not to be anti-competitive under a non-discrimination clause.

For competition policy, it is important to recognize that anti-competitive passive ownership in common suppliers is profitable when there is both up- and downstream competition and thus foreclosure potentially not the main concern. Most importantly, proposing passive backwards ownership in a supplier as a remedy to a proposed vertical merger tends not to benefit competition but eventually worsens the competitive outcome, as long as upstream competition is effective and the upstream supplier serves competitors of the raider. The reason is that full vertical integration tends to remove double marginalization via joint control, whilst partial backwards integration tends to enhance that.

In the present setting, we abstract from other, potentially socially desirable motives for partial backwards ownership. A particularly important effect is the mitigation of agency problems in case of firm-specific investments (Riordan, 1991; Dasgupta and Tao, 2000) such as investment in specific R\&D. Indeed, Allen and Phillips (2000) show for a sample of US companies that vertical partial ownership is positively correlated with a high R\&D intensity. Yet such potentially pro-competitive effects need to be weighed against the anti-competitive effects of passive backwards integration presented here. 


\section{Appendix: Proofs}

Proof of Proposition 1. Suppose for the moment that only downstream firm $i$ holds shares in $U$, i.e. $\delta_{i}>\delta_{-i}=0$. The first order condition $\frac{\partial \Pi_{-i}}{\partial p_{-i}}=0$ implied by (11) and, hence, the best-reply $p_{-i}^{r}\left(p_{i}\right)$ of $-i$ is independent of $\delta_{i}$. In contrast, the marginal profit $\frac{\partial \Pi_{i}}{\partial p_{i}}$ increases in $i^{\prime} s$ ownership share $\delta_{i}$. This implies a higher best reply $p_{i}^{r}\left(p_{-i} \mid \delta_{i}\right)$ for any given $p_{-i}$. By continuity, $\frac{\partial p_{i}^{r}\left(p_{-i} \mid \delta_{i}\right)}{\partial \delta_{i}}>0$. Strategic complementarity of downstream prices implies that an increase in $\delta_{i}$ increases both equilibrium prices. This argument straightforwardly extends to the case where both firms hold shares in $U$ because $\frac{\partial^{2} \Pi_{i}}{\partial p_{i} \partial \delta_{-i}} \geq 0$.

Proof of Proposition 2. Differentiating the combined profits of $A$ and $U$ with respect to $\delta_{A}$ and using that $\delta_{B}=0$ yields

$$
\frac{d \Pi_{A}^{U}}{d \delta_{A}}=\left(p_{A}^{*} \frac{\partial q_{A}}{\partial p_{A}}+q_{A}^{*}+c \frac{\partial q_{B}}{\partial p_{A}}\right) \frac{d p_{A}^{*}}{d \delta_{A}}+\left(p_{A}^{*} \frac{\partial q_{A}}{\partial p_{B}}+c \frac{\partial q_{B}}{\partial p_{B}}\right) \frac{d p_{B}^{*}}{d \delta_{A}} .
$$

Clearly, at $c=0$, the derivative is equal to zero as $d p_{i}^{*} / d \delta_{A}=0$ (the upstream margin is zero). To assess the derivative for small, but positive $c$, further differentiate with respect to $c$ to obtain

$$
\begin{aligned}
\frac{d^{2} \Pi_{A}^{U}}{d \delta_{A} d c}= & \frac{d}{d c}\left(p_{A}^{*} \frac{\partial q_{A}}{\partial p_{A}}+q_{A}^{*}+c \frac{\partial q_{B}}{\partial p_{A}}\right) \frac{d p_{A}^{*}}{d \delta_{A}}+\frac{d}{d c}\left(p_{A}^{*} \frac{\partial q_{A}}{\partial p_{B}}+c \frac{\partial q_{B}}{\partial p_{B}}\right) \frac{d p_{B}^{*}}{d \delta_{A}} \\
& +\left(p_{A}^{*} \frac{\partial q_{A}}{\partial p_{A}}+q_{A}^{*}+c \frac{\partial q_{B}}{\partial p_{A}}\right) \frac{d^{2} p_{A}^{*}}{d \delta_{A} d c}+\left(p_{A}^{*} \frac{\partial q_{A}}{\partial p_{B}}+c \frac{\partial q_{B}}{\partial p_{B}}\right) \frac{d^{2} p_{B}^{*}}{d \delta_{A} d c} .
\end{aligned}
$$

Evaluating this derivative at $c=0$ yields

$$
\left.\frac{d^{2} \Pi_{A}^{U}}{d \delta_{A} d c}\right|_{c=0}=\left.p_{A}^{*} \partial_{p_{B}} q_{A}^{*} \frac{d^{2} p_{B}^{*}}{d \delta_{A} d c}\right|_{c=0}
$$

because $\left.\frac{d p_{A}^{*}}{d \delta_{A}}\right|_{c=0}=\left.\frac{d p_{B}^{*}}{d \delta_{A}}\right|_{c=0}=0$ and $p_{A} \frac{\partial q_{A}}{\partial p_{A}}+q_{A}=0$ (this is the FOC of $\pi_{A}$ with respect to $p_{A}$ at $c=0$ ). Recall that $\frac{d p_{B}^{*}}{d \delta_{A}}>0$ for $c>0$ (Proposition 1) while $\frac{d p_{B}^{*}}{d \delta_{A}}=0$ at $c=0$. By continuity, this implies $\left.\frac{d^{2} p_{B}^{*}}{d \delta_{A} d c}\right|_{c=0}>0$. It follows that $\left.\frac{d^{2} \Pi_{A}^{U}}{d \delta_{A} d c}\right|_{c=0}>0$ which, by continuity, establishes the result.

Proof of Proposition 3. The best response function of $A$ under complete separation is characterized by

$$
\frac{\partial \Pi_{A}}{\partial p_{A}}=\left(p_{A}-c\right) \frac{\partial q_{A}}{\partial p_{A}}+q_{A}\left(p_{A}, p_{B}\right)=0 .
$$

When maximizing the integrated profit $p_{A} q_{A}+w_{B} q_{B}$, it is - as argued before - still optimal to serve $B$ at $w_{B} \leq c$ and, hence, the corresponding downstream price reaction is characterized by

$$
p_{A} \frac{\partial q_{A}}{\partial p_{A}}+q_{A}\left(p_{A}, p_{B}\right)+w_{B} \frac{\partial q_{B}}{\partial p_{A}}=0 .
$$

Subtract the left hand side (lhs) of (16) from the lhs of (17) to obtain $\Delta \equiv c \frac{\partial q_{A}}{\partial p_{A}}+$ $w_{B} \frac{\partial q_{B}}{\partial p_{A}}$. The symmetric fixed point under separation $\left(\delta_{A}=\delta_{B}=0\right)$ must have $p_{A}=p_{B}$. This implies $\frac{\partial q_{B}}{\partial p_{A}}=\frac{\partial q_{A}}{\partial p_{B}}$. Hence, at equal prices, $\Delta$ is negative as $-\frac{\partial q_{A}}{\partial p_{A}}>\frac{\partial q_{A}}{\partial p_{B}}>0$ by 
Assumption 1 and $w_{B} \leq c$. A negative $\Delta$ implies that the marginal profit of $A$ under integration is lower and thus the integrated $A$ wants to set a lower $p_{A}$. The best-reply function of $B$ is characterized by

$$
\frac{\partial \Pi_{B}}{\partial p_{B}}=\left(p_{B}-y\right) \frac{\partial q_{B}}{\partial p_{B}}+q_{B}\left(p_{B}, p_{A}\right)=0
$$

with $y=c$ under separation and $y=w_{B} \leq c$ under integration of $A$ and $U$. Hence the best reply function $p_{B}^{r}\left(p_{A}\right)$ of $B$ is (weakly) lower under integration. Taken together, strategic complementarity (Assumption 3) implies that the unique fixed point of the downstream prices under integration must lie strictly below that under separation.

Proof of Lemma 2. We look at the joint profit $\Pi_{A}^{U}$ of $A$ and $U$ when we move from vertical separation to vertical integration. Recall that under effective competition, the upstream firm, integrated or not, will always set the maximal input price $w_{B}^{*}=c$ when selling to firm $B$, and this independently of any choice of $w_{A}$. Also recall that $\Pi_{A}^{U}=p_{A}^{*} q_{A}\left(p_{A}^{*}, p_{B}^{*}\right)+c q_{B}\left(p_{B}^{*}, p_{A}^{*}\right)$. Let the equilibrium downstream prices as a function of input prices be given by $p_{A}^{*}\left(w_{A}, c\right) \equiv \arg \max _{p_{A}} p_{A} q_{A}\left(p_{A}, p_{B}^{*}\right)+c q_{B}-w_{A}\left[q_{A}+q_{B}\right]$ and $p_{B}^{*}\left(c, w_{A}\right) \equiv \arg \max _{p_{B}}\left(p_{B}-c\right) q_{B}\left(p_{B}, p_{A}^{*}\right)$. Note that $w_{A}=0$ yields the downstream prices under integration, and $w_{A}=c$ those under separation.

The effect of an increase of $w_{A}$ on $\Pi_{A}^{U}$ is determined by implicit differentiation. This yields

$$
\frac{d \Pi_{A}^{U *}}{d w_{A}}=\frac{d \Pi_{A}^{U *}}{d p_{A}^{*}} \frac{d p_{A}^{*}}{d w_{A}}+\frac{d \Pi_{A}^{U *}}{d p_{B}^{*}} \frac{d p_{B}^{*}}{d w_{A}}
$$

First, Assumptions 1-4 imply that at $w_{A}=c$ and hence $p_{A}^{*}=p_{B}^{*}$, we have both $\frac{d p_{A}^{*}}{d w_{A}}>0$ and $\frac{d p_{B}^{*}}{d w_{A}}>0$ for $c \geq 0$. Second,

$$
\frac{d \Pi_{A}^{U *}}{d p_{A}^{*}}=\underbrace{q_{A}\left(p_{A}^{*}, p_{B}^{*}\right)+\left(p_{A}^{*}-c\right) \frac{\partial q_{A}}{\partial p_{A}}}_{=0}+c \underbrace{\left[\frac{\partial q_{A}}{\partial p_{A}}+\frac{\partial q_{B}}{\partial p_{A}}\right]}_{<0 \text { at } p_{A}=p_{B}}<0,
$$

but approaches 0 as $c$ goes to zero. Third, $\frac{d \Pi_{A}^{U *}}{d p_{B}^{*}}=p_{A}^{*} \frac{\partial q_{A}}{\partial p_{B}}+c \frac{\partial q_{B}}{\partial p_{B}}$ is strictly positive for $c$ sufficiently close to zero. In consequence, $\left[\frac{d \Pi_{A}^{U *}}{d p_{B}^{*}} \frac{d p_{B}^{*}}{d w_{A}}\right]_{w_{A}=c}>0$ dominates $\left[\frac{d \Pi_{A}^{U *}}{d p_{A}^{*}} \frac{d p_{A}^{*}}{d w_{A}}\right]_{w_{A}=c}<$ 0 as $c$ goes to zero. Summarizing, $\left.\frac{d \Pi_{A}^{U *}}{d w_{A}}\right|_{w_{A}=c}>0$ for $c$ sufficiently small. By continuity, decreasing $w_{A}$ from $c$ to 0 decreases $\Pi_{A}^{U *}$ for $c$ sufficiently small which implies that moving from separation to integration is strictly unprofitable.

Proof of Lemma 4. Suppose that firm $-i$ sources only from $U$. The most attractive contract that $V$ can offer $i$ must yield $V$ zero profits, i.e. $f_{i}^{V}=x_{i}^{V} \cdot\left(c-w_{i}^{V}\right)$, with $x_{i}^{V}$ denoting the quantity sourced by $i$ from $V$. Given $w_{i}^{U} \leq c$, the arbitrage possibility due to multiple sourcing renders contracts with $w_{i}^{V}>c$ and thus $f_{i}^{V}<0$ unprofitable as $x_{i}^{V}$ would be 0 . Recall that $p_{i}^{*}\left(w_{i}, w_{-i}\right)$ denotes the downstream equilibrium price of $i$ as a function of the marginal input prices. The net profit of $i$ when buying all inputs from $V$ 
is given by

$$
\Pi_{i}=\left(p_{i}^{*}\left(w_{i}^{V}, w_{-i}^{U}\right)-w_{i}^{V}\right) q_{i}\left(p_{i}^{*}\left(w_{i}^{V}, w_{-i}^{U}\right), p_{-i}^{*}\left(w_{-i}^{U}, w_{i}^{V}\right)\right)-f_{i}^{V}
$$

Substituting for $f_{i}^{V}$ using the zero profit condition of $V$ with $x_{i}^{V}=q_{i}$ yields

$$
\Pi_{i}=\left(p_{i}^{*}\left(w_{i}^{V}, w_{-i}^{U}\right)-c\right) q_{i}\left(p_{i}^{*}\left(w_{i}^{V}, w_{-i}^{U}\right), p_{-i}^{*}\left(w_{-i}^{U}, w_{i}^{V}\right) .\right.
$$

Increasing $w_{i}^{V}$ at $w_{i}^{V}=c$ is profitable if $d \Pi_{i} /\left.d w_{i}^{V}\right|_{w_{i}^{V}=c}>0$. Differentiation yields

$$
d \Pi_{i} / d w_{i}^{V}=\frac{d \Pi_{i}}{d p_{i}^{*}} \frac{d p_{i}^{*}}{d w_{i}^{V}}+\frac{d \Pi_{i}}{d p_{-i}^{*}} \frac{d p_{-i}^{*}}{d w_{i}^{V}}
$$

Optimality of the downstream prices implies $\frac{d \Pi_{i}}{d p_{i}^{*}}=0$. Moreover, $\frac{d p_{-i}^{*}}{d w_{i}^{V}}>0$ follows from the strategic complementarity of downstream prices, and with it, the supermodularity of the downstream pricing subgame. Finally, $\frac{d \pi_{i}}{d p_{-i}^{*}}>0$ follows directly from $\frac{\partial q_{i}}{\partial p_{-i}}>0$ (substitutable products). Combining these statements yields

$$
\left.\frac{d \Pi_{i}}{d w_{i}^{V}}\right|_{w_{i}^{V}=c}=\frac{d \Pi_{i}}{d p_{-i}^{*}} \frac{d p_{-i}^{*}}{d w_{i}^{V}}>0 .
$$

This implies that raising $w_{i}^{V}$ above $c$ would be profitable for $i$. However, the no arbitrage condition and $w_{i}^{U} \leq c$ renders this impossible. Analogously, decreasing $w_{i}^{V}$ below $c$ and adjusting $f_{i}^{V}$ to satisfy zero profits of $V$ is not profitable for $i$. In consequence, the contract offer of $V$ most attractive to any downstream firm $i$ is given by $\{0, c\}$.

Proof of Proposition 4. Recall that for marginal input prices of $w_{i}$ and $w_{-i}, i^{\prime} s$ equilibrium downstream price is given by $p_{i}^{*}\left(w_{i}, w_{-i}\right)$. Also recall that $\pi_{i}^{*}\left(w_{i}, w_{-i}\right) \equiv\left[p_{i}^{*}\left(w_{i}, w_{-i}\right)-w_{i}\right]$. $q_{i}\left(p_{i}^{*}\left(w_{i}, w_{-i}\right), p_{-i}^{*}\left(w_{-i}, w_{i}\right)\right)$ and substitute for $\pi_{i}^{*}$ in $(14)$ to obtain

$$
\begin{aligned}
\pi^{U} & =\sum_{i} p_{i}^{*}\left(w_{i}, w_{-i}\right) \cdot q_{i}\left(p_{i}^{*}\left(w_{i}, w_{-i}\right), p_{-i}^{*}\left(w_{-i}, w_{i}\right)\right) \\
& -\sum_{i}\left(p_{i}^{*}\left(c, w_{-i}\right)-c\right) q_{i}\left(p_{i}^{*}\left(c, w_{-i}\right), p_{-i}^{*}\left(w_{-i}, c\right)\right) .
\end{aligned}
$$

The first sum captures the industry profits and the second, as $\{0, c\}$ is $V$ 's tariff that maximizes the downstream firms' profits, the value of each of the downstream firms' outside option. An obvious candidate equilibrium tariff of $U$ is $\left\{f^{*}=0, w^{*}=c\right\}$ to both downstream firms. This results in $\pi^{U}=2 c q_{i}\left(p^{*}(c, c), p^{*}(c, c)\right)$. Let $\left\{f^{*}, w^{*}\right\}$ denote alternative symmetric equilibrium candidates offered by $U$. Recall that $w^{*}>c$ with $f^{*}<0$ is not feasible, as then the downstream firms would source all quantities from $V$. Towards assessing whether $U$ would benefit from lowering $w$ below $c$ (and increasing $f$ ), we differentiate $\pi^{U}$ with respect to $w$ at and evaluate it at $w=c$. If that sign is positive for $w_{i}, i \in\{A, B\}$ separately and jointly, then $U$ has no incentive to decrease its price 
below $c$. Differentiation of $\pi^{U}$ with respect to $w_{i}$ yields

$$
\begin{aligned}
\frac{d \pi^{U}}{d w_{i}}=\frac{\partial p_{i}^{*}}{\partial w_{i}} q_{i}+p_{i}^{*} \cdot\left(\frac{\partial q_{i}}{\partial p_{i}} \frac{\partial p_{i}^{*}}{\partial w_{i}}+\frac{\partial q_{i}}{\partial p_{-i}} \frac{\partial p_{-i}^{*}}{\partial w_{i}}\right)+\frac{\partial p_{-i}^{*}}{\partial w_{i}} q_{-i}+p_{-i}^{*} \cdot\left(\frac{\partial q_{-i}}{\partial p_{i}} \frac{\partial p_{i}^{*}}{\partial w_{i}}+\frac{\partial q_{-i}}{\partial p_{-i}} \frac{\partial p_{-i}^{*}}{\partial w_{i}}\right) \\
-\frac{\partial p_{-i}^{*}}{\partial w_{i}} q_{-i}-\left(p_{-i}^{*}-c\right)\left(\frac{\partial q_{-i}}{\partial p_{-i}} \frac{\partial p_{-i}^{*}}{\partial w_{i}}+\frac{\partial q_{-i}}{\partial p_{i}} \frac{\partial p_{i}^{*}}{\partial w_{i}}\right)
\end{aligned}
$$

Evaluating the derivative at $w_{i}=c$, subtracting and adding $c \frac{\partial q_{i}}{\partial p_{i}} \frac{\partial p_{i}^{*}}{\partial w_{i}}$, making use of downstream firm $i$ 's FOC $\frac{\partial \pi_{i}}{\partial p_{i}}=0$ and simplifying, we obtain

$$
\frac{d \pi^{U}}{d w_{i}}=c\left[\frac{\partial q_{i}}{\partial p_{i}} \frac{\partial p_{i}^{*}}{\partial w_{i}}+\frac{\partial q_{-i}}{\partial p_{-i}} \frac{\partial p_{-i}^{*}}{\partial w_{i}}+\frac{\partial q_{-i}}{\partial p_{i}} \frac{\partial p_{i}^{*}}{\partial w_{i}}+\frac{\partial q_{i}}{\partial p_{-i}} \frac{\partial p_{-i}^{*}}{\partial w_{i}}\right]+\left[p_{i}^{*}-c\right] \frac{\partial q_{i}}{\partial p_{-i}} \frac{\partial p_{-i}^{*}}{\partial w_{i}}
$$

Substituting for $p_{i}^{*}-c$ from the FOC $\frac{\partial \pi_{i}}{\partial p_{i}}=0$ yields that $\frac{d \pi^{U}}{d w_{i}}>0$ iff

$$
c<\frac{q_{i}}{-\left(\frac{\partial q_{i}}{\partial p_{i}}+\frac{\partial q_{i}}{\partial p_{-i}}\right)} \cdot \frac{\frac{\partial q_{i}}{\partial p_{-i}}}{-\frac{\partial q_{i}}{\partial p_{i}}} \cdot \frac{\frac{\partial p_{i}^{*}}{\partial w_{-i}}}{\frac{\partial p_{i}^{*}}{\partial w_{i}}+\frac{\partial p_{i}^{*}}{\partial w_{-i}}}
$$

The rhs of (19) remains positive as $c$ goes to zero. Hence (19) holds for $c$ sufficiently small. This establishes the result.

\section{References}

Allain, M.L., C. Chambolle, and P. Rey, "Vertical Integration, Innovation and Foreclosure," 2010.

Allen, J.W. and G.M. Phillips, "Corporate equity ownership, strategic alliances, and product market relationships," The Journal of Finance, 2000, 55 (6), 2791-2815.

Bernheim, B.D. and M.D. Whinston, "Common marketing agency as a device for facilitating collusion," The Rand Journal of Economics, 1985, pp. 269-281.

Bonanno, G. and J. Vickers, "Vertical separation," The Journal of Industrial Economics, 1988, 36 (3), 257-265.

Bork, R.H., "The antitrust paradox: A policy at war with itself," New York, 1978, 1993.

Bourreau, M., J. Hombert, J. Pouyet, and N. Schutz, "Upstream Competition between Vertically Integrated Firms," The Journal of Industrial Economics, 2011, 59 (4), 677-713.

Brito, D., L. Cabral, and H. Vasconcelos, "Duopoly Competition with Competitor Partial Ownership," 2010.

Chen, Y., "On vertical mergers and their competitive effects," The Rand Journal of Economics, 2001, 32 (4), 667-685. 
- and M.H. Riordan, "Vertical integration, exclusive dealing, and expost cartelization," The Rand Journal of Economics, 2007, 38 (1), 1-21.

Choi, J.P. and S.S. Yi, "Vertical foreclosure with the choice of input specifications," The Rand Journal of Economics, 2000, 31 (4), 717-743.

Dasgupta, S. and Z. Tao, "Bargaining, bonding, and partial ownership," International Economic Review, 2000, 41 (3), 609-635.

Fee, C.E., C.J. Hadlock, and S. Thomas, "Corporate equity ownership and the governance of product market relationships," The Journal of Finance, 2006, 61 (3), $1217-1251$.

Fershtman, C., K.L. Judd, and E. Kalai, "Observable contracts: Strategic delegation and cooperation," International Economic Review, 1991, pp. 551-559.

Flath, D., "Vertical integration by means of shareholding interlocks," International Journal of Industrial Organization, 1989, 7 (3), 369-380.

- "When is it rational for firms to acquire silent interests in rivals?," International Journal of Industrial Organization, 1991, 9 (4), 573-583.

Fudenberg, D. and J. Tirole, "The fat-cat effect, the puppy-dog ploy, and the lean and hungry look," The American Economic Review, 1984, 74 (2), 361-366.

Greenlee, P. and A. Raskovich, "Partial vertical ownership," European Economic Review, 2006, 50 (4), 1017-1041.

Güth, W., N. Nikiforakis, and H.-T. Normann, "Vertical cross-shareholding: Theory and experimental evidence," International Journal of Industrial Organization, 2007, $25(1), 69-89$.

Hart, O. and J. Tirole, "Vertical integration and market foreclosure," Brookings Papers on Economic Activity. Microeconomics, 1990, 1990, 205-286.

Höffler, F. and S. Kranz, "Imperfect legal unbundling of monopolistic bottlenecks," Journal of Regulatory Economics, 2011, pp. 1-20.

_ and _, "Legal unbundling can be a golden mean between vertical integration and ownership separation," International Journal of Industrial Organization, 2011.

Hunold, M., L.-H. Röller, and K. Stahl, "Ownership and Control in Vertically Related Firms," 2011. Working paper.

Karle, H., T. Klein, and K. Stahl, "Ownership and Control in a Competitive Industry," 2011.

O'Brien, D.P. and S.C. Salop, "Competitive effects of partial ownership: Financial interest and corporate control," Antitrust Law Journal, 1999, 67, 559.

Ordover, J.A., G. Saloner, and S.C. Salop, "Equilibrium vertical foreclosure," The American Economic Review, 1990, 80 (1), 127-142. 
Posner, R.A., Antitrust Law: An Economic Perspective, University of Chicago Press, 1976.

Riordan, M.H., "Ownership without control: Toward a theory of backward integration," Journal of the Japanese and International Economies, 1991, 5 (2), 101-119.

Sandonis, J. and R. Fauli-Oller, "On the competitive effects of vertical integration by a research laboratory," International Journal of Industrial Organization, 2006, 24 (4), 715-731.

Tirole, J., "Industrial organization," Cambridge and London, 1988. 